\title{
Introduction
}

\section{Creative Practices/Resistant Acts}

Nesreen Hussein and Iain MacKenzie

\begin{abstract}
In the opening of this special issue, we invite readers to consider, through the articles presented, how various modes of artistic expression and creative acts of resistance can lead to a better understanding of the nature and implications of political and social revolt, and how a focus on creative practices can be part of the wider debate in a time of uncertainty and unrest. The issue examines the important intersection between creative practices and acts of resistance from an interdisciplinary perspective with a focus on the Middle East and North Africa (MENA) and Mediterranean regions. The introduction aims to frame the problems presented by the sphere of creative practices of resistance and clarify what is at stake with a view to providing impetus for further research into this critical aspect of contentious politics. It concludes by tracing how the general framing of the problems operates within and through the different articles.
\end{abstract}

Keywords: acts of resistance, Arab Spring, creative practices, Mediterranean, MENA, political revolt, social revolt

This special issue was motivated by an interdisciplinary symposium organized in May 2012 at the Institute of Contemporary Arts in London under the title "Creative Practices/Resistant Acts: Cultural Production and Emerging Democracies in Revolutionary Nations." ${ }^{1}$ The symposium brought together artists, activists, and scholars from various backgrounds, cultural traditions, and political contexts to bring into dialogue different modes of engaging with, and understanding, "creative practices" as acts of resistance in times of political unrest. The contributors presented artistic, political, historical, and analytical perspectives from Egypt, Syria, Palestine, Greece, and Germany. In different ways, the contributions 
emphasized the power of art and creative acts in fueling global mobilizations, destabilizing hegemonic narratives of oppression, and reclaiming people's sense of empowerment, belonging, and identity. They ranged between paper presentations, performative demonstrations, live participatory performance, and roundtable discussions. One of the common threads that brought the contributions together, and that initiated the conceptualization of the event, was a shared understanding of revolutions as inherently "creative acts." Those acts are not only manifest in the proliferation of forms of artistic expression and modes of resistance that consciously utilize creative tools but are also evident in how spontaneous and organized acts of resistance transform public spaces and urban geography "performatively" as a response to the transformation in people's attitudes toward the status quo. Demonstrations, marches, occupations, and various acts of civil disobedience mark the formation of "alternative communities" that find a platform for the re-formed narratives of democracy in various mediums and artistic traditions. ${ }^{2}$ In different ways, the contributors examined the role of "creative practices" in generating new understandings of citizenship, democracy, agency, and identity within forms that include the performed as well as the performative.

Notably, the symposium was held less than two years after the first sparks of the Arab Spring were ignited in Tunisia at the end of 2010, which was followed by the revolutions that spread around the Middle East and North Africa (MENA) region. During those revolutions, diverse art forms were reclaimed or reshaped-from graffiti to street performance to song and poetry, intervening in the spaces of authority and subverting dynamics of oppression. The poignancy and affectivity of those forms as "tools" for resistance and expression-as well as the gravity, impact, and the sociopolitical implications of the revolutionscould not have passed unacknowledged without trying to engage with them and with different perspectives from and about them in an exchange that took place within the artistic, scholarly, and international community in the United Kingdom. ${ }^{3}$ The fruitful exchanges led to our urge to document and extend the experience to some extent to a wider audience in the form of a publication with an interdisciplinary emphasis aimed at a diverse readership. The time distance between holding the symposium and the publication of this special issue saw significant shifts in the sociopolitical and cultural landscapes in the MENA region and beyond, following the Arab revolutions.

Nevertheless, the relevance of the contributions remains ever more present and pressing, for the issues they raise start in specific moments in time but then are usefully extended into wider consequences that go 
beyond temporal strictures. And at a time of critical transformations in today's global politics and power structures, when public conversations about identity, belonging, and collective action could not be more important, the articles in this issue provide valuable opportunities to reflect on the resistive power of art and creative acts and their ability to intervene in political discourse during critical times in potent and affective ways. The articles are opportunities to ask, would a close examination of artistic expression and creative acts of resistance lead to a better understanding of the nature and implications of political and social revolt? In a time of uncertainty, when nations undergo political and social changes, how can a focus on creative practices be part of the wider debate about the current state of affairs, as well as the debate about our futures? What kinds of trajectories can be drawn between revolutions and popular uprisings in different regional and global communities, and how can this be identified in acts of resistance?

In response to the above questions, among others summarized below, the collection includes both developments on papers presented at the symposium as well as entirely new works. The result is an issue that joins a body of scholarly and literary work that emerged in the wake of the Arab Spring. These include, for example, the special issue of Theatre Research International on "Theatre and the Arab Spring," edited by Hazem Azmy and Marvin Carlson (2013), and the special issue of Contemporary Theatre Review titled "Theatre, Performance and Activism: Gestures towards an Equitable World,” edited by Jenny Hughes and Simon Parry (2015). While these two important journal issues eloquently look at the myriad ways by which theater and performance can offer tools to make better sense of the complex sociocultural and political realities defining this era, in relation to the Arab Spring as well as other contexts of activism, this issue here extends its critical frameworks into the fields of politics and literature in addition to theater and performance in a conscious attempt to bridge the gap between the social sciences and the humanities, as well as to foster a multitude of voices. By implication, Contention: The Multidisciplinary Journal of Social Protest presented itself as an appropriate home for the issue. The journal's multidisciplinary approach to the study of collective actions, social movements, and other forms of political and social contention responds aptly to the interdisciplinary scope of the issue. Its interest in reconstructing the fragmentation of the scientific discourse by hosting a diversified range of contributions from different theoretical, methodological, and philosophical approaches ideally extends one of our aims, exemplified in our collaboration as coeditors. Bringing together discourses from the 
fields of theater, performance studies, literature, and politics plays a part in challenging the polarization inherent in perceptions around those disciplines, highlighting the interrelationship between art and creative practices on one hand and politics and resistant acts on the other.

\section{Framing the Problems}

The area of overlap between creative practices and acts of resistance has become both larger and more obscure. In this issue, we explore this overlap from the perspective of different disciplines with a focus on the MENA and Mediterranean regions. By way of introduction, however, we aim to frame the problems presented by this increased domain of creative practices of resistance and, in the process, clarify what is at stake with a view to providing impetus for further research into this important aspect of contentious politics. While the articles in this issue demonstrate that any analysis of the roles, functions, and effects of creative practices of resistance requires an in-depth, almost ethnographic, concern with the detail of what happened in any given situation, they do also point to intriguing ways of framing these insights as contributions to a general theory of how creative practices and resistant acts may be thought to intersect. With that in mind, we shall begin with reflections on the different ways the relationship between art and politics has been modeled and how one model in particular opens up the interesting domain of creative practices and resistant acts in ways that the others do not. It will become apparent that at the juncture of creative practices and resistant acts, one finds the notion of the event. How one then articulates this notion does much to shape the frame one places around the relationship between creative practices and resistant acts. We conclude by discussing how this general framing of the problems operates within and through the articles in this special issue.

\section{Art and Politics}

In her book Art and Politics: A Small History of Art for Social Change since 1945, Claudia Mesch (2013) provides a compelling account of how artists have contributed to social and political change since the end of World War II. Tackling a range of key themes, including postcolonialism, feminism, and antiglobalization, Mesch (2013: 2) frames her account with a clear statement of how she understands the relationship 
between art and politics. She claims, "Certain artists and the works they created intentionally contributed to the construction of new political or social consciousness, and ... artists continue to believe, to the present day, that their art can be and is political in nature." This view of the relationship between art and politics, we suggest, neatly encapsulates the "contributory" model with which we can begin our survey of the different ways in which these domains interact. The fundamental idea of this model is that art and artists are able to contribute to political and social debate at the level of more or less intentional interventions in the political domain. This model presumes there is a domain of the political-Mesch refers to it as "the activity of collective or group decision-making that also affects other groups within that social body"within which art is able to contribute both inventive formulations of key issues and imaginative solutions to the political debates of the age. Importantly, Mesch recognizes that such contributions can be both state sponsored and directed against the activities of the state-be they war, colonization, or the juridical frameworks that have denied whole sections of the population equal rights. Furthermore, she details how propagandist art came from both sides of the Cold War, and, regardless of which side it came from, state-sponsored artists produced some of the most striking and long-lasting images of modern and contemporary art. Similarly, the antistate art that came to prominence in the 1960s was by no means homogeneous in style or content and, indeed, was often compromised by its relation to state-sponsored activities. In this way, a complicated and intriguing picture of the intertwined worlds of post-World War II art and politics emerges. For all of this complexity, however, the overarching framework is one that presumes a domain of politics to which art contributes.

One of the tensions within this contributory model is related to the nature and scope of art vis-à-vis politics. In the comment quoted above, for example, Mesch slips from a claim about "certain artists" to one about "artists," and equivocates about whether art "can be" or "is" political in nature. Ultimately, we suggest, she remains uncertain as to whether all artists are engaged in politics and all art is political. This uncertainty is productive from the perspective of art history, with which she is primarily concerned, because it keeps open the possibility of different contributions to politics from a variety of different artists and art forms. However, from the perspective of social and political theory, this openness comes at the cost of closing down what we understand by politics and the political. Perhaps there is a different way of theorizing the relationship between art and politics that does not set limits to 
our understanding of politics and the political. In fact, this is how we suggest one could understand the influential work of Jacques Rancière.

Notably in his book The Politics of Aesthetics: The Distribution of the Sensible, Rancière (2004) develops an alternative to the contributory model of the relationship between art and politics. Developing his earlier work on Michel Foucault, Rancière proffers what we call a "constitutive" model to account for this relationship. On this model, the everyday domain of politics is simply that which polices the senses, whereas the redistribution of this policed world is an intrinsically artistic practice that constitutes radically new political interventions in the everyday world of policed relationships. This constitutive model, therefore, rests on the presumption that the domain of the senses is primary to the practices that organize it by way of decision-making collectives, as Mesch puts it. As such, the domain of art conditions the world of politics, and through artistic intervention, new understandings of the political are constituted. As with Mesch, Rancière's constitutive model offers a similarly complex rendering of the effects of this reversal of the priorities between art and politics. It enables him, for example, to give a particularly clear appreciation of the aesthetic regime of modernity's shortcomings and the claims of the avant-garde (2004: 20-30). But the overall shape of the proposition is clear: the aesthetic domain constitutes its own "meta-politics" and, as such, undercuts contributory models with a more radical model of the aesthetic as constitutive of political redistributions of the policed world of everyday politics.

For all that his model may offer a radical redrawing of the relationship between art and politics, tensions remain. According to Peter Osborne (2013), for example, Rancière's account of the constitutive and disruptive power of art leads to a politically conservative retrenchment of the political nature of art within the abstract realm of the aesthetic. Or as Eric Alliez and Osborne (2013: 10) ask, "Can the aesthetic image distinguish itself from or within the spectacle of capital-becomingimage?" Perhaps Rancière's emphasis on the constitutive role of art in the public sphere makes it difficult to demarcate art that resists and art that becomes subsumed within that which it is trying to resist?

Both the contributory and constitutive accounts, therefore, seem plausible and yet open to concerns about the nature and scope of art vis-à-vis politics and the risk of artistic practice becoming subsumed within the object of its critique. Is there a way of conceiving of the relationship between art and politics, from the perspective of resistance to established orders, that captures both the contributory and the constitutive dimensions without the associated dangers? 


\section{Creative Practices/Resistant Acts: A Process-Oriented View of the Problem}

The problem of the relationship between art and politics can be phrased in this way: is it possible to conceptualize the relationship between art and politics in a manner that doesn't nest these domains one within the other in a latent disciplinary hierarchy? Is there a way of talking about the deeply connected relationship between art and politics that nonetheless accords an equal status to both these domains, thereby avoiding the traps of either a limited concept of the political or art's potential subsumption within the state and capital? In reaching for an answer to these questions, we must first address two preliminary issues. First, can we specify more precisely what is meant by art and politics in the context of contentious politics? Second, how might greater specification aid our reconceptualization of the relationship between art and politics in the context of such contentious politics?

Considerable conceptual slippage is already evident in some of the key terms concerning the relationship between art and politics, not least that these are contested concepts in their own right. Addressing this relationship from the perspective of contemporary forms of contentious politics already engenders the first important clarification. The focus on contentious politics brackets questions relating to the composition and nature of social movements qua movements, in order to draw attention to forms of protest and resistance that may emanate from them and from elsewhere. Hence, the importance of the concept of "resistant acts," where these are understood as what a political actor does in defiance of established regimes of power (see Caygill 2013). The "political actor" may be an individual artist or activist but may also be a collectivity and indeed a constellation of particular forces that include not merely human agents. ${ }^{4}$ There is no doubt that this initial specification of the need to focus on resistant acts raises important philosophical issues. However, the aim in the first instance is to shift the terms of the debate in such a way as, momentarily at least, to bracket off the problems associated with the terms "politics" and "social movement," neither of which in themselves are intrinsically tied to the idea of resistance.

Some preliminary remarks on the side of art can also be established. Those who talk about art often presume it is the product of an individual artist, usually a (male) tortured genius; that art must be displayed in an art institution, public or private, for it to be considered art; and that artists always produce an art object, be it a painting, musical score, playscript, sculpture, and so on. However, each of these 
key assumptions has been called into question in the developments of contemporary art-developments, for example, that include collectives engaging the public in sites beyond the gallery and museum in ways that do not leave an art object behind (see, e.g., Thompson 2012 for a useful collection discussing some of these themes). While increasingly commonplace in debates within contemporary art, being wary of presuming too much about what constitutes an artist and an art object has not, with some exceptions, found its way into discussions regarding the interface of art and politics. ${ }^{5}$ With this in mind, we propose that it is more conceptually precise to talk of "creative practices" than simply of "art" when thinking about the "art-politics" nexus in the context of contentious politics. Creative practices, to offer up a definition, are repeated activities that work on the given (be it material, psychic, organic, collective, and so on) in order to make a difference. Accepting that there is a nebulous quality to this definition, it nonetheless wards off hasty assumptions about the nature of art and shifts our theoretical focus toward both those practices that are self-proclaimed artistic interventions and to those that make a difference to our experience of the world without being overtly declared works of art.

While these conceptual definitions go some way toward sloughing off a set of presumptions about politics, social movements, artists, and artworks that may otherwise muddy the waters, a more positive implication is worth stressing. The insistence on "resistant acts" and "creative practices" opens up the idea that a connection between acts and practices may aid our understanding of their relationship. This connection can be conceived in two related ways. First, it suggests there is a sense in which a creative practice and a resistant act may be part of the same "process." This is important because it takes us away from the often-implicit reification of the terms "art" and "politics" that follows from our implicit reification of the artist and political actor. The concept of "resistant acts" emphasizes the act of resistance itself and makes no hasty judgments about the author of the act; similarly, the idea of "creative practice" is employed to focus on the repeated activity of altering the world of shared experiences without presuming too much about artistic agency in the background, so to speak. Behind the act and the repeated act or practice resides not the actor or artist but the process in which both are involved. Second, this specification, and the process-oriented view it engenders, needs to be tempered by our insistence on the idea that creative practices are not always resistant acts and vice versa. In other words, we must specify that only under certain conditions do these two tendencies join forces in the same process. We can, however, think through 
these conditions in a general manner: whatever the relationship between creative practices and resistant acts, something happens in both cases. When that which happens is a significant challenge to the established orders (artistic and political but also material, psychic, and so on), we are led to the idea that they may be part of the same event, even if spatially and temporally distinct. In this way, therefore, it is possible to conceive of a processual relationship between creative practices and resistant acts in the sense that they form distinct parts of the same event.

The processual model of the relationship between creative practices and resistant acts, in drawing our attention to the fact that they are related processes within the same event, leads us away from presumptions about the thinglike qualities of the domains of either art or politics that tend to result, as we saw above, in hierarchical accounts of that relationship. Furthermore, we are then able to conceive of what happens as not simply contributory or constitutive but as potentially both. Creative practices may contribute to and constitute resistant acts, and resistant acts may contribute to and constitute creative practices. The relationship between them is one of mutuality rather than hierarchy. In short, this reframing of the problem establishes the mutually contributory and constitutive nature of the art-politics relationship under conditions of contentious politics. The primary theoretical innovation that enables this reframing is the evental status of both acts (that manifest practices) and practices (made manifest in repeated acts). Much could be said, philosophically, about the relationship between processes, events, practices, and acts (e.g., MacKenzie and Porter 2011; Williams 2016), and setting out this framework here is simply the first step in a discussion of how we might bring this philosophical work to bear on matters of contentious politics. We now turn to the articles in this special issue in order to convey how this processual model of the relationship between creative practices and resistant acts resonates with the detailed analysis each author offers of the recent uprisings in the MENA and Mediterranean regions.

\section{Article Summaries}

While there is no substitute for in-depth engagement with each of the articles in this volume, as they are all richly detailed and reflective accounts of the intersection of creative practices and resistant acts, certain themes can be elaborated as we summarize their respective contributions. Each of the articles conveys the importance of viewing the processes that join creative practices and resistant acts from within-in the language of 
process philosophy, immanently. They also demonstrate that the events under discussion are always multidimensional in respect to the processes they express and to the intrinsic complexities that arise within creative practices and resistant acts when viewed distinctly. It might be thought that these two general features-an immanent understanding of the complexities of particular events-might make analysis difficult if not impossible from the perspective of social science aimed at generalization. And yet, they all equally convey that the view from within can also profitably provoke further conceptual and empirical work in contexts outside of those directly addressed. One might go further; an immanent, processual, and event-oriented account of the relationship between creative practices and resistant acts is not only possible but also necessary if we are to shed light and clarity on this increasing domain of contentious politics. In this respect, we can see the value of working at the interface of the humanities and social sciences.

In "Flying above Bloodshed: Performative Protest in the Scared City of Damascus," Ziad Adwan analyzes the "flying protests" that took place in Syria in 2011. These protests emerged quickly and dissolved just as quickly, thereby making it difficult for the Syrian authorities to act in time to stop them or detain those involved. Bringing the language of theater to his analysis, Adwan constructs a compelling account of how and why these flying protests worked so well. As he notes, while the protestors may not have been consciously aware of creating theatrical moments, thinking of the flying protests in this way proffers a mode of understanding that is often missed by social scientists who tend to dismiss or downplay the fleeting and ephemeral. Adwan's participation in these flying protests was in the form of both actor and spectator. One of the benefits of a theatrical analysis is that it makes clear that both of these perspectives are internal, or immanent, to the events themselves. Another benefit is that it gives a rich set of reflections on the dynamics of performance and drama within the protests themselves and in the game of cat and mouse with the Syrian authorities. The moments of intensity that accompanied these protests made the negotiation of the performance and the drama a process of constant adjustment and action in the heat of the moment. As he concludes, the flying protests made it clear that contentious politics is not always about who is stronger but rather who is quicker.

In her contribution “'For a Martyr from Afar': A Response to Laila Soliman's No Time for Art," Caroline Rooney delves deeply into the nature of the relationship between creative practices and resistant acts from the side of one particular creative practice. Where Adwan addresses this 
relationship by considering the theatrical nature of a series of fleeting resistant acts, Rooney develops her reflections through a self-consciously creative practice that seems almost indistinguishable from a resistant act itself. Taken together, they provide two (of many) imperceptible sides of the same event. Laila Soliman's No Time for Art is a documentary performance series that operates on several levels at once: it brings into view the courage of the Egyptian revolutionaries and the brutality waged against them, invites audience participation as an act of memory but also advocacy on behalf of the martyrs, combines visual and auditory elements in a compelling mix of courtroom and public square, and much else besides. In her response, Rooney eloquently draws out many of these complexities based on her own viewing of, and participation in, one production in the series. At stake is nothing less than the nature of activist art in times of crisis and the contribution of such art in forging the bonds of collective solidarity out of subjective artistic intervention. One of the conclusions Rooney draws out is that unfinished, unending art will always allow for the engendering of its resistant and activist trajectories.

While flying protests and a documentary performance series may appear to have the processual and evental built in, so to speak, there may be reservations regarding how well this model of the relationship between creative practices and resistant acts fits with what we often assume are more traditional sedentary forms of public demonstration, such as occupying major metropolitan squares. The articles by Ayman ElDesouky and George Sotiropoulos show that this is not the case, at least considering the recent occupations of Tahrir and Syntagma. In his contribution, El-Desouky conceptualizes the "connective agency" that resulted from the deployment of Egyptian cultural practices called amāra. Forms of chanting, sloganeering, sculpting, and much more combined to create a cultural space within Tahrir that drew out and reconstituted modes of Egyptian identity in a dynamic reiterative fashion. Theorizing this effect with the help of Badiou, Žižek, and Rancière, El-Desouky shows convincingly the integral nature of such cultural creative practices to the resistant act of occupation. One of the key conclusions is the importance we should give to the resonance of such practices as they emanate from the event of occupation throughout Egypt, to the present day, and across the world. Such resonance is an immanent feature of the event itself, ultimately unbounded by space and time.

Turning to Syntagma, Sotiropoulos approaches many of the same issues but from the perspective of political philosophy. Once again, addressing these issues with the sensitivities of a participant-observer allows for a nuanced and convincing account of the internal dynamics 
of the square movement at Syntagma-one that gives voice to the complexities of the guiding sign of that process, "real democracy." In many respects, this motif is a well-worn, even tired, sign around which to rally. Sotiropoulos shows that, even so, the processes involved in articulating and enacting this motif in Syntagma were far from exhausted or exhaustive. Indeed, as the argument progresses, it becomes increasingly clear that there is an inexhaustible nature to this motif, one that echoes in a distant but distinct manner the inexhaustibility of the artwork that Rooney addresses. Where unending art engages resistance in new and demanding ways, so too can unending claims for real democracy be said to engage creative practice in new and demanding ways.

Much in the articles of this special issue pushes against the process-oriented model of creative practices and resistant acts that we have outlined here, and much remains to be specified. But the collection as a whole makes it clear that there is ample scope for further research into this most pressing aspect of contentious politics. Where art and politics meet, in the dynamics of creative practices and resistant acts, surprising conclusions follow about the nature of contentious politics, the nature of art, and the nature of their relationship. This is surely worthy of continuing research.

Nesreen Hussein is a Lecturer in Contemporary Theater at Middlesex University London. Her current research focuses on performance and activism in relation to issues of agency, identity, and belonging. Her publications on this topic include "Cairo: My City, My Revolution" in Performance and the Global City, edited by D. J. Hopkins and Kim Solga (2013), and "Gestures of Resistance between the Street and the Theatre: Documentary Theatre in Egypt and Laila Soliman's No Time for Art" (Contemporary Theatre Review, 2015). In 2011, she was awarded the Helsinki Essay Prize and the New Scholars' Prize from the International Federation for Theatre Research.

Iain MacKenzie is a Co-director of the Centre for Critical Thought and Senior Lecturer in Politics in the School of Politics and International Relations at the University of Kent. He is the author of The Idea of Pure Critique (2004), co-author of Dramatizing the Political: Deleuze and Guattari (2011, with Robert Porter), and co-editor of Marxism, Religion and Ideology: Themes from David McLellan (2015, with David Bates and Sean Sayers) and The Edinburgh Companion to Poststructuralism (2013, with Benoît Dillet and Robert Porter). 


\section{Notes}

1. The symposium was a collaboration between the School of Arts and the School of Politics and International Relations at the University of Kent, Canterbury. The Faculty of Humanities' Strategic Research Development Fund as well as the School of Politics and International Relations Research Support Fund both provided financial support for this event.

2. For an account of how "urban transformations" can demonstrate a "performative" impulse and foster grassroots democracy, see Hussein (2013).

3. One of the contributors, Ziad Adwan, could not join the symposium from Syria due to the rejection of his visa application to enter the United Kingdom. His contribution, however, is included in this collection.

4. Jane Bennett's (2010) discussion of the role of "vibrant matter" is instructive in this latter respect.

5. One interesting exception is Alina Jelinek's This Is Not Art: Activism and Other Non-Art (2013).

\section{References}

Alliez, Eric, and Peter Osborne, eds. 2013. Spheres of Action: Art and Politics. London: Tate.

Bennett, Jane. 2010. Vibrant Matter: A Political Ecology of Things. Durham, NC: Duke University Press.

Caygill, Howard. 2013. On Resistance: A Philosophy of Defiance. London: Bloomsbury.

Hussein, Nesreen. 2013. "Cairo: My City, My Revolution.” In Performance and the Global City, ed. D. J. Hopkins and Kim Solga, 223-244. London: Palgrave.

Jelinek, Alison. 2013. This Is Not Art: Activism and Other Non-Art. London: I.B. Tauris.

MacKenzie, Iain, and Robert Porter. 2011. Dramatizing the Political: Deleuze and Guattari. London: Palgrave.

Mesch, Claudia. 2013. Art and Politics: A Small History of Art for Social Change since 1945. London: I.B. Tauris.

Osborne, Peter. 2013. Anywhere or Not at All: Philosophy of Contemporary Art. London: Verso.

Rancière, Jacques. 2004. The Politics of Aesthetics: The Distribution of the Sensible. London: Continuum.

Thompson, Nato. 2012. Living as Form: Socially Engaged Art from 1991-2011. Cambridge, MA: MIT Press.

Williams, James. 2016. A Process Philosophy of Signs. Edinburgh: Edinburgh University Press. 